\title{
How front-line healthcare workers respond to stock-outs of essential medicines in the Eastern Cape Province of South Africa
}

\author{
R Hodes, ${ }^{1}$ DPhil, MSc; I Price, ${ }^{2}$ BSc; N Bungane, ${ }^{1}$ BCur Hons, E Toska, ${ }^{1}$ DPhil, MSc; L Cluver, ${ }^{3}$ DPhil, MPhil \\ ${ }^{1}$ AIDS and Society Research Unit, Centre for Social Science Research, University of Cape Town, South Africa \\ ${ }^{2}$ Mathematical Institute, Oxford University, UK \\ ${ }^{3}$ Child and Family Social Work, Department of Social Policy and Intervention, Oxford University, UK; and Department of Psychiatry and \\ Mental Health, Faculty of Health Sciences, University of Cape Town, South Africa
}

Corresponding author: $R$ Hodes (rebecca.hodes@gmail.com)

\begin{abstract}
Shortages of essential medicines are a daily occurrence in many of South Africa (SA)'s public health facilities. This study focuses on the responses of healthcare workers to stock-outs, investigating how actors at the 'front line' of public health delivery understand, experience and respond to shortages of essential medicines and equipment in their facilities. Findings are based on focus groups, observations and interviews with healthcare workers and patients at healthcare facilities in the Eastern Cape Province of SA, conducted as part of the Mzantsi Wakho study. The research revealed a discrepancy between 'informal' definitions of stock-outs and their reporting through formal stockout management channels. Front-line healthcare workers had designed their own systems for classifying the severity of stock-outs, based on the product in question, and on their potential to access stocks from other facilities. Beyond formal systems of procurement and supply, healthcare workers had established vast networks of alternative communication and action, often using personal resources to procure medical supplies. Stock-outs were only reported when informal methods of stock-sharing did not secure top-up supplies. These findings have implications for understanding the frequency and severity of stock-outs, and for taking action to prevent and manage stock-outs effectively.
\end{abstract}

S Afr Med J 2017;107(9):738-740. DOI:10.7196/SAMJ.2017.v107i9.12476

In the decades since South Africa (SA)'s first democratic elections, the policies and programmes that direct the provision of public healthcare have been radically revised. ${ }^{[1-3]}$ A growing literature reveals gaps between the state's policy and legislative commitments to improving public healthcare, ${ }^{[3-8]}$ and on-the-ground challenges that continue to obstruct public access. ${ }^{[1,9,10]}$ It focuses on the functioning of health systems ${ }^{[3,11-13]}$ and on the operational aspects of clinical care. ${ }^{[14-19]}$

While the National Department of Health is committed to improving access to medicine, the procurement and distribution of medical supplies remains inadequate in many health districts. ${ }^{[20]}$ Research on stock-outs has strived to quantify the extent and severity of shortages of medical supplies. It has identified which drugs and medical products are most commonly depleted, including through research on tracer medicines that represent procurement and provision challenges. ${ }^{[21-25]}$ A national audit published by the Health Systems Trust (HST) of healthcare facilities' compliance with key priorities included a measure on 'availability of medicines and supplies. The Eastern Cape Province's compliance score for this was $54 \%$ in 2012 . The audit also found an extremely high failure percentage (77\%) in clinics for the measure 'Tracer medicines as per applicable Essential Drugs List or formulary are available in the pharmacy/medicine. ${ }^{\text {[3] }}$

Stock-outs arise from an inability to manage medical supplies, report shortages, and act swiftly and effectively to prevent their recurrence. Stock-outs are intertwined with other challenges in the health sector, including shortages of healthcare workers, inadequate training, weak oversight and management, and inadequate monitoring and evaluation of clinic data. ${ }^{[3]}$
From research and policy perspectives, it is crucial to understand: (i) whether formal reporting is an accurate measure of available medical supplies; and (ii) how front-line healthcare providers experience and respond to stock-outs at facilities level. Insights from healthcare workers are key to design and implement interventions to reduce stock-outs and limit their adverse effects on patients.

\section{Methods}

This study focused on the qualitative dimension of stock-outs, examining how healthcare providers perceived and responded to shortages of medical supplies in their facilities. It was conducted as a sub-study within the Mzantsi Wakho study on the health of adolescents in the Eastern Cape. ${ }^{[23,26]}$ Facilities were selected on two bases: range of service level (including two clinics, a community health centre, a district hospital and a tertiary hospital) and willingness of healthcare workers to participate in direct observations and interviews, including within waiting rooms and dispensaries. Ethical approval for this study was provided by research ethics committees at the University of Cape Town (ref. no. UCT/CSSR/1/2014(ii)) and the University of Oxford (ref. no. SSD/CUREC2/12-21).

Between December 2013 and May 2016, researchers conducted over 1000 hours of observation at public healthcare facilities. We interviewed 15 healthcare workers, including senior staff (hospital CEOs, doctors, nurse managers, nurses and community health workers), administrative staff (receptionists and data managers) and ground staff (including cleaners, gardeners and security guards). In April 2016, we conducted five interviews with healthcare workers involved specifically in providing and monitoring medical supplies at five facilities. We conducted a focus group with 19 research staff 
of the Mzantsi Wakho study, which included nurses and community healthcare workers. The focus group was recorded and transcribed, translated and coded by two qualitative researchers and the study's senior clinics researcher. To ensure the confidentiality of research participants at clinics, interviews at healthcare facilities were not audio-recorded. Findings are based on the themes that emerged from these multiple qualitative methods and data sources, developed iteratively, over the course of 31 months of observations, interviews and participatory research. This primary research was supplemented by a review of public health research, policy plans and guidelines on stock-outs in SA.

\section{Findlings}

The management of medical stocks, including ordering, receiving, dispensing and reporting, depended on the structure and staffing of facilities. In better-resourced facilities, such as hospitals, these roles were performed by dedicated pharmacists and pharmacy assistants. In smaller facilities, including those serving large patient populations, nurses performed these roles alongside other duties as healthcare providers and administrators. Of the 3074 clinics surveyed in the HST's National Healthcare Facilities Baseline Audit, 'a high $84 \%$ had no input from a Pharmacist or Pharmacy Assistant Post-Basic.. ${ }^{[3]}$ At one clinic within this dedicated study, a nurse who also served as clinic manager laughed when asked if her facility had a pharmacist. 'You are looking at her,' she replied.

\section{Stock-outs and supply-sharing networks}

Definitions and understandings of stock-outs varied considerably between different facilities, and in relation to different drugs. All five facilities in this study reported frequent stock-outs of numerous products listed on the Essential Medicines List. ${ }^{[7]}$ At a rural clinic, the dispensary was run by a nurse who served as the facility's operations manager. The clinic had no pharmacist or pharmacy assistant, and at the time of the interview had stocked out of Kaletra. At a larger urban clinic, the pharmacy assistant reported having no stock of folic acid, simvastatin, electrolyte solution or gauze on the day of the interview.

The nurse at the first clinic contacted other clinics in the district and borrowed Kaletra to avoid turning patients away without their medicines. However, because she did not capture and report the shortage, no stock-out had officially occurred. At the second facility, items reported as stock-outs were those that the pharmacy assistant was not able to borrow from nearby clinics - either because they were experiencing the same shortages or because they lacked sufficient 'buffer stock' to share. The front-line healthcare workers interviewed did not generally report drug shortages using official channels if they could access top-up supplies from a neighbouring facility. Only stock-outs of supplies that were 'unborrowable' were reported.

The 'borrowing' phenomenon is a crucial component of practical monitoring and oversight of medical supplies in the Eastern Cape. While this is the phrase commonly used by healthcare workers, 'borrowing' is not strictly an accurate description of this practice. As the head pharmacist at a public hospital explained, 'We say "borrowed", but no-one ever returns.' Nurses, pharmacists and pharmacy assistants within the province had established networks of communication and exchange to manage this alternative supply system. These networks were informal and internal, established by healthcare workers as a means of dealing directly with stock-outs themselves. Their boundaries did not correspond with the official zoning of health districts and municipalities.

This study explored how these networks functioned. When a clinic was running low on a particular drug or piece of equipment, the staff member tasked with managing medical supplies would contact a staff member from another clinic - often via Whatsapp - and ask if they could 'lend' supply. Healthcare workers used personal resources to tap into these networks, including personal cell phones (mobile phones) and 'airtime.'[27] This practice of sharing essential medicines happened 'all the time', according to the head pharmacist at a district hospital, and was recounted by staff members within all facilities in the study. Staff reported that, through this exchange, they were 'almost always' able to deal with the shortages they faced.

This thriving parallel economy in medicines supply is far from the ideal of robust procurement and regulation. All facilities within this study, with the exception of the hospitals, struggled to provide sustained, uninterrupted access to essential medical supplies. But this study also demonstrated that informal economies of medicines exchange, established by healthcare workers, often had the potential to address stock-outs quickly and effectively, providing healthcare workers with direct, rapid access to 'buffer stocks' from neighbouring facilities. The successes of these informal networks were premised on high degrees of personal motivation among staff, their ability to design, implement and adapt contingency plans, their collegiality, and their investment in providing continuous, reliable treatment.

While some stock-outs may have been dealt with effectively by 'borrowing and sharing', 'full-blown' stock-outs were also reported among healthcare workers and patients in this study. A full-blown stock-out was when borrowing medical supply in advance of a total depletion, or as an interim short-term strategy, had failed. This resulted in patients being turned away from facilities without prescribed medicines. At times, patients were advised by nurses or community healthcare workers to travel to other facilities presumed to have better stocks. Through trial and error, patients had themselves ascertained which facilities reliably stocked the chronic medicines they needed, and sought healthcare there despite greater travel and time costs.

At a day hospital, a community health worker recounted common 'full-blown' stock-outs of paracetamol and vitamin B complex. While she acknowledged that these medicines were unavailable at the facility, she maintained that shortages were minor in comparison with primary facilities in urban townships and rural areas in the district:

'There are clinics in the location - yoh, people are moaning. They are running out of things. Then the patients flock here ... [My patient]'s grandmother is staying in a rural area. She [the grandmother] and grandfather didn't get their medication for two months. And another lady ... she was supposed to get 10 of her [blood pressure] medicines. But she only got two of the 10.'

This healthcare worker described another strategy used by frontline providers to limit the negative health impacts of stock-outs on patients. In cases of diminishing supply, healthcare workers might provide patients with a partial prescription, advising them to return to the clinic for the rest of their regimen in the coming days. The effects of this practice on patient retention require further research, particularly in the context of chronic conditions that require consistent, reliable access to medicines.

\section{Discussion}

The government has recognised the urgency of stock-outs, and committed to improving monitoring and accountability in the health sector. A proliferation of plans and circulars captures attempts to improve procurement and oversight of medical supplies, and to systematise how these are reported and resolved. A proposed digital stock-monitoring system has the potential to improve how stock-outs are detected, but its success depends on investments in 
technology and infrastructure at facility level. If proposed initiatives for improving medical supplies are to have an optimal impact, they must be accompanied by attendant investments in human resources. For the front-line healthcare workers in this study, reporting on medicines supply was already a distraction from primary care. A shortage of data capturers in facilities meant that nurses were often tasked with completing paperwork for monitoring and evaluation, with the risk that reporting on healthcare delivery took priority over delivery itself.

Different definitions of stock-outs must be considered in designing accurate monitoring mechanisms, and in conducting future research with healthcare providers.

The impact of stock-outs on patients and staff would be far more severe were it not for the existence of collaborative and resourceful informal networks of healthcare workers and facilities who share and redistribute medical supplies. The number of 'full-blown' stock-outs was considerably smaller than the number of 'minor' stock-outs, that were managed through borrowing, and often went unreported. Moreover, healthcare workers were more likely to report shortages or absences of 'high-profile' drugs, for conditions that attracted greater clinical and public scrutiny. Shortages of 'routine' medical supplies, such as surgical scissors, and 'nice-to-haves', such as pain medications and vitamins, were accepted as an everyday reality and feature of the constrained public health system.

\section{Conclusion}

Informal networks of communication and exchange enable frontline healthcare workers to respond quickly and effectively to stockouts of essential medical supplies. Interviews and observations with these healthcare workers, conducted within a longitudinal study on healthcare in the Eastern Cape, reveal how these networks function outside of formal supply chains and management structures. Interventions to improve the monitoring of medical supplies should recognise that interpretations of stock-outs vary widely, and that healthcare workers may circumvent formal processes to expedite access to buffer stocks at neighbouring facilities. This study points to the latent capacity for drug supply monitoring, and reveals a flourishing informal system of supply and exchange within the public health system.

Acknowledgements. We thank the healthcare workers and patients interviewed. The Mzantsi Wakho research team hosted this sub-study. We gratefully acknowledge the collaboration of Lizzy Button, Craig Carty, Marisa Casale, Jenny Doubt, Lesley Gittings, Nonkumbuzo Galela, Eda He, Chunyiswa Kama, Ntombohlanga Beauty Kamile, Bulelani Kinana, Vuyiseka Luke, Zoliswa Marikeni, Thembani Mampangashe, Amanda Mbiko, Franziska Meinck, Philiswa Mjo, Sindiswa Mona, Mavis Mpumlwana, Siyavuya Mqalo, Sinazo Mwellie, Moses Neel, Nisso Nurova, Bongiwe Saliwe, Izidora Skracic and Prince Tshefote. Francois Venter, Sue Tafeni, Mara Kardas-Nelson, Musaed Abrahams, Catherine Tomlison, Sarah Goodwin, Deborah Posel and Gil Yaron provided further insights. Author contributions. RH, IP and NB designed the study and conducted primary research. All the authors analysed and reviewed findings. RH and IP drafted the first version of the manuscript, which all the authors edited and reviewed.

Funding. Funding for this research was provided by Evidence for HIV Prevention in Southern Africa, a programme of the UK Department for
International Development, managed by Mott MacDonald (MM/EHPSA/ UCT/05150014), the Nuffield Foundation under grant CPF/41513, UNICEF South Africa, and the Make All Voices Count Initiative, through Stop Stockouts.

Conflicts of interest. None.

1. Harrison D. An Overview of Health and Health Care in South Africa 1994 - 2010: Priorities, Progres and Prospects for New Gains. Washington, DC: Henry J Kaiser Family Foundation, 2009.

2. Sanders D, Chopra M. Key challenges to achieving health for all in an inequitable society: The case of South Africa. Am J Public Health 2006;96(1):73-78. https://doi.org/10.2105\%2Fajph.2005.062679

3. Visser R, Bhana R, Monticelli F. The National Health Care Facilities Baseline Audit National Summary Report. Durban: Health Systems Trust, 2012

4. National Department of Health, South Africa. National Core Standards for Health Establishments in South Africa. Pretoria: NDoH, 2011. http://www.rhap.org.za/wp-content/uploads/2014/05/NationalCore-Standards-2011-1.pdf (accessed 18 January 2017).

5. National Department of Health, South Africa. National Strategic Plan on HIV, STIs and TB, 2012 National Department of Health, South Africa. National Strategic Plan on HIV, STIs and TB, 2012
- 2016. Pretoria: NDoH, 2011. http://www.gov.za/sites/www.gov.za/files/national\%20strategic\%20 2016. Pretoria: NDoH, 2011. http://www.gov.za/sites/www.gov.za/files/
lan\%20on\%20hiv\%20stis\%20and\%20tb_0.pdf (accessed 18 January 2017).

6. National Department of Health, South Africa. Policy on Quality in Health Care for South Africa. Pretoria: NDoH, 2007. http://www.gov.za/sites/www.gov.za/files/qhc-policy.pdf (accessed 18 January 2017)

7. Leong T, de Waal R, Munsamy J, van de Wal B, Jamaloodien K, eds. Standard Treatment Guidelines and Essential Medicines List for South Africa. Pretoria: National Department of Health, 2014 http://www. kznhealth.gov.za/pharmacy/edlphc2014a.pdf (accessed 17 January 2017).

8. Republic of South Africa. Operation Phakisa: Ideal Clinic Realisation and Maintenance: Final Lab Report. 2015. https://www.idealclinic.org.za/docs/2016/phakisa/Operation\%20Phakisa\%20Ideal\%20 Clinic\%20Realisaation\%20\&\%20Maintenance\%20Final\%20report\%20May\%202015.pdf (accessed 17 January 2017).

9. Schneider H, Blaauw D, Gilson L, Chabikuli N, Goudge J. Health systems and access to antiretroviral drugs for HIV in southern Africa: Service delivery and human resources challenges. Reprod Health Matters 2006;14(27):12-23. https://doi.org/10.1016\%2Fs0968-8080\%2806\%2927232-x

10. Suri A, Gan K, Carpenter S. Voices from the field: Perspectives from community health workers on Suri A, Gan K, Carpenter S. Voices from the field: Perspectives from community health workers on
health care delivery in rural KwaZulu-Natal, South Africa. J Infect Dis 2007;196(Suppl 3):S505-S511. health care delivery in rural KwaZu/u-
https://doi.org $/ 10.1086 \% 2 \mathrm{~F} 521122$

11. Schneider H, Coetzee D, van Rensburg D, Gilson L. Differences in antiretroviral scale up in three South African provinces: The role of implementation management. BMC Health Serv Res 2010;10(1):S4 http://dx.doi.org/10.1186\%2F1472-6963-10-s1-s4

12. Pattinson RC, ed. Saving Mothers 2011-2013: The Sixth Report of the National Committee for Confidential Enquiries into Maternal Deaths in South Africa. Pretoria: Government Printer, 2014 http://www.kznhealth.gov.za/mcwh/Maternal/Saving-Mothers-2011-2013-short-report.pdf (accessed 18 January 2017).

3. Bateman C. Inept drug supply management causing stock-outs. S Afr Med J 2015;105(9):706-707 https://doi.org/10.7196\%2Fsamjnew.8543

14. Harries $\mathrm{AD}$, Zachariah $\mathrm{R}$, Lawn $\mathrm{SD}$, Rosen $\mathrm{S}$. Strategies to improve patient retention on antiretroviral therapy in sub-Saharan Africa. Trop Med Int Health 2010;15(s1):70-75. https://doi. org/10.1111\%2Fj.1365-3156.2010.02506.x

15. Bekker LG, Venter F, Cohen K, et al. Provision of antiretroviral therapy in South Africa: The nuts and . Bekker LG, Venter F, Cohen K, et al. Provision of antiretroviral therapy in South
bolts. Antivir Ther 2014;19(Suppl 3):105-116. https://doi.org/10.3851/IMP2905

16. Van Wyk SS, Reid AJ, Mandalakas AM, et al. Operational challenges in managing isoniazid preventive

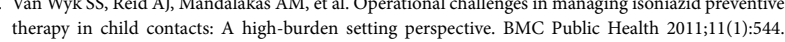
https://doi.org/10.1186/1471-2458-11-544

17. Mayosi BM, Benatar SR. Health and healthcare in South Africa - 20 years after Mandela. N Engl J Med 2014;371(14):1344-1353. https://doi.org/10.1056/NEJMsr1405012

18. Churchyard GJ, Mametja LD, Mvusi L, et al. Tuberculosis control in South Africa: Successes, challenge and recommendations. S Afr Med J 2014;104(3):234-248. https://doi.org/10.7196/SAMJ.7689

19. Goudge J, Gilson L, Russell S, Gumede T, Mills A. Affordability, availability and acceptability barrier to health care for the chronically ill: Longitudinal case studies from South Africa. BMC Health Serv Res 2009;9(1):75. https://doi.org/10.1186/1472-6963-9-75

20. Coovadia H, Jewkes R, Barron P, Sanders D, McIntyre D. The health and health system of South Africa: Historical roots of current public health challenges. Lancet 2009;374(9692):817-834. https://doi. org $110.1016 \% 2$ Fs $0140-6736 \% 2809 \% 2960951-x$

21. Stop Stockouts. South Africa: Monitoring Essential Medicines Consortium. South Africa: Stop Stop Stockouts. South Africa: Monitoring Essential Medicines Consortium. South Africa: Stop
Stockouts, 2016 (updated 18 January 2017). http://www.stockouts.org (accessed 22 January 2017).

22. Stop Stockouts, South Africa. Stockouts in South Africa - a national crisis. 2013. http://stockouts.org/ Downloads/stop_stockouts_report_2013pdf_1.pdf (accessed 20 January 2017).

23. Cluver LD, Toska E, Orkin FM, et al. Achieving equity in HIV-treatment outcomes: Can social protection improve adolescent ART-adherence in South Africa? AIDS Care 2016;28(Suppl 2):73-82. https://doi.org/10.1080\%2F09540121.2016.1179008

24. Doctors Without Borders, Rural Doctors Association of Southern Africa, Rural Health Advocac Project, Treatment Action Campaign, SECTION27, Southern African HIV Clinicians Society. 2015 Stock Outs National Survey. South Africa: Stop Stockouts, June 2016. http://stockouts.org/ Downloads/2015_stock_outs_national_survey.pdf (accessed 18 January 2017).

25. Magadzire BP, Ward K, Leng HM, Sanders D. Inefficient procurement processes undermine access to medicines in the Western Cape Province of South Africa. S Afr Med J 2017;107(7):581-584. https://doi org/10.7196/SAMJ.2017.v107i7.11356

26. Mzantsi Wakho. 2010 [updated 17 November 2016]. http://www.mzantsiwakho.org.za (accessed 22 January 2017).

27. Sips I, Mazanderani AH, Schneider H, Greeff M, Barten F, Moshabela M. Community care workers, poor referral networks and consumption of personal resources in rural South Africa. PLoS One 2014;9(4):e95324. http://dx.doi.org/10.1371\%2Fjournal.pone.0095324 